\title{
Exertional dyspnoea in COPD: the clinical utility of cardiopulmonary exercise testing
}

\author{
Denis E. O'Donnell ${ }^{1}$, Amany F. Elbehairy ${ }^{1,2}$, Azmy Faisal ${ }^{1,3}$, Katherine A. Webb ${ }^{1}$, \\ J. Alberto Neder ${ }^{1}$ and Donald A. Mahler ${ }^{4}$
}

Number 2 in the Series “Exertional Dyspnoea”
Edited by Pierantonio Laveneziana and Piergiuseppe Agostoni

Affiliations: ${ }^{1}$ Dept of Medicine, Queen's University and Kingston General Hospital, Kingston, ON, Canada. ${ }^{2}$ Dept of Chest Diseases, Faculty of Medicine, Alexandria University, Alexandria, Egypt. ${ }^{3}$ Faculty of Physical Education for Men, Alexandria University, Alexandria, Egypt. ${ }^{4}$ Geisel School of Medicine at Dartmouth, Hanover, NH, USA.

Correspondence: Denis E. O'Donnell, 102 Stuart Street, Kingston, ON, Canada, K7L 2V6.

E-mail: odonnellaqueensu.ca

ABSTRACT Activity-related dyspnoea is often the most distressing symptom experienced by patients with chronic obstructive pulmonary disease (COPD) and can persist despite comprehensive medical management. It is now clear that dyspnoea during physical activity occurs across the spectrum of disease severity, even in those with mild airway obstruction. Our understanding of the nature and source of dyspnoea is incomplete, but current aetiological concepts emphasise the importance of increased central neural drive to breathe in the setting of a reduced ability of the respiratory system to appropriately respond. Since dyspnoea is provoked or aggravated by physical activity, its concurrent measurement during standardised laboratory exercise testing is clearly important. Combining measurement of perceptual and physiological responses during exercise can provide valuable insights into symptom severity and its pathophysiological underpinnings. This review summarises the abnormal physiological responses to exercise in COPD, as these form the basis for modern constructs of the neurobiology of exertional dyspnoea. The main objectives are: 1) to examine the role of cardiopulmonary exercise testing (CPET) in uncovering the physiological mechanisms of exertional dyspnoea in patients with mild-to-moderate COPD; 2) to examine the escalating negative sensory consequences of progressive respiratory impairment with disease advancement; and 3) to build a physiological rationale for individualised treatment optimisation based on CPET.

0 $@$ ERSpublications

Measurement of symptom intensity, ventilatory control and mechanics during exercise exposes mechanisms of dyspnoea http://ow.ly/6OXQ3020tEA

\section{Introduction}

Chronic obstructive pulmonary disease (COPD) is a common and often devastating respiratory illness that afflicts $\sim 10 \%$ of individuals over 40 years of age $[1,2]$. The most common symptom experienced by patients with COPD is perceived respiratory discomfort (dyspnoea) during physical activity. According to the 2012 American Thoracic Society statement, breathlessness (or dyspnoea) is "a subjective experience of breathing discomfort that consists of qualitatively distinct sensations that vary in intensity" [3]. Effective management of this troublesome symptom, and the associated poor health status, represents a major

Editorial comment in Eur Respir Rev 2016; 25: 227-229.

Previous articles in this series: No. 1: Dubé B-P, Agostoni P, Laveneziana P. Exertional dyspnoea in chronic heart failure: the role of the lung and respiratory mechanical factors. Eur Respir Rev 2016; 25: 317-332.

Received: June 022016 | Accepted after revision: July 012016

Conflict of interest: Disclosures can be found alongside this article at err.ersjournals.com

Provenance: Submitted article, peer reviewed.

Copyright OERS 2016. ERR articles are open access and distributed under the terms of the Creative Commons Attribution Non-Commercial Licence 4.0. 
challenge for caregivers. Chronic breathlessness, reduced exercise capacity and habitual physical inactivity are inexorably linked and are strong predictors of reduced survival in COPD [4-7]. It is no surprise, therefore, that expert guidelines committees uniformly recommend improvement of dyspnoea and exercise tolerance as a major goal of management [8-10].

Dyspnoea assessment is an integral component of the general clinical evaluation of the COPD patient and is usually achieved by careful history. The patient is questioned about the onset, frequency and duration of the symptom (including aggravating and relieving factors, frequency of rescue use of short-acting bronchodilators, etc.) and its impact on daily activities. The clinician determines the magnitude of the physical task required to provoke dyspnoea in the individual and is encouraged to record this using a simple questionnaire such as the Medical Research Council (MRC) scale [8, 9]. However, it is generally accepted that such clinical assessments can substantially underestimate the actual degree of activity-related dyspnoea as patients gradually adapt to the presence of unpleasant symptoms by increasingly avoiding activities that provoke them in the first place. Thus, an all too common observation is that many patients with COPD, who claim not to be particularly troubled by activity-related dyspnoea, experience significant respiratory discomfort at low-work intensities during formal cardiopulmonary exercise testing (CPET) compared with healthy age-matched peers [11]. Moreover, traditional resting pulmonary function tests correlate poorly with severity of activity-related dyspnoea $[12,13]$. The current review, therefore, examines the clinical rationale for dyspnoea assessment during CPET in the context of our current understanding of the pathophysiology of this symptom in COPD [3, 14-16]. To better understand the mechanisms of dyspnoea, we will first review the abnormal physiological responses to exercise in patients with COPD.

\section{Physiological responses to exercise}

Increased efferent respiratory drive

The well-established physiological abnormalities that are amplified during the stress of exercise in patients with moderate COPD, when compared with healthy controls, are highlighted in figure 1 [17]. These include high central inspiratory neural drive from cortical and bulbo-pontine centres in the brain, as indirectly indicated by relatively increased fractional inspiratory neural drive to the diaphragm. Increased efferent
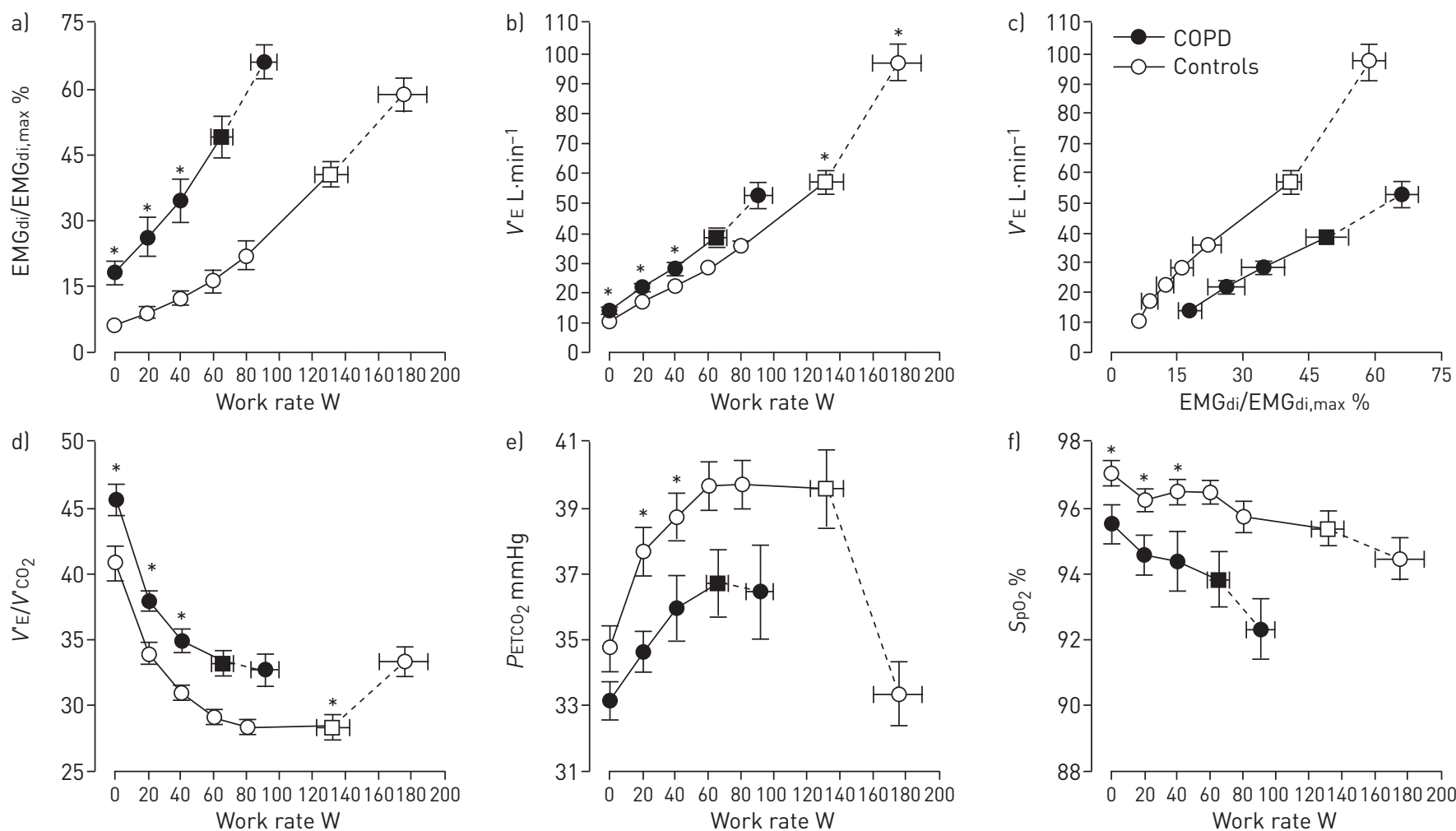

FIGURE 1 a-f) Diaphragm electromyography (EMGdi) and selected ventilatory and indirect gas exchange responses to incremental cycle exercise test in patients with moderate chronic obstructive pulmonary disease (COPD) and age-matched healthy controls. Data are presented as mean \pm SEM. Square symbols represent tidal volume-ventilation inflection points. EMGdi/EMGdi,max: an index of inspiratory neural drive to the crural diaphragm; $V^{\prime} E$ : minute ventilation; $V^{\prime} E / V^{\prime} \mathrm{CO}_{2}$ : ventilatory equivalent for carbon dioxide; $P \mathrm{ETCO}$ : partial pressure of end-tidal carbon dioxide; $\mathrm{SpO}_{2}$ : arterial oxygen saturation measured by pulse oximetry. ${ }^{*}: \mathrm{p}<0.05$ for COPD versus healthy controls at rest, at standardised work rates or at peak exercise. Reproduced and modified from [17] with permission. 

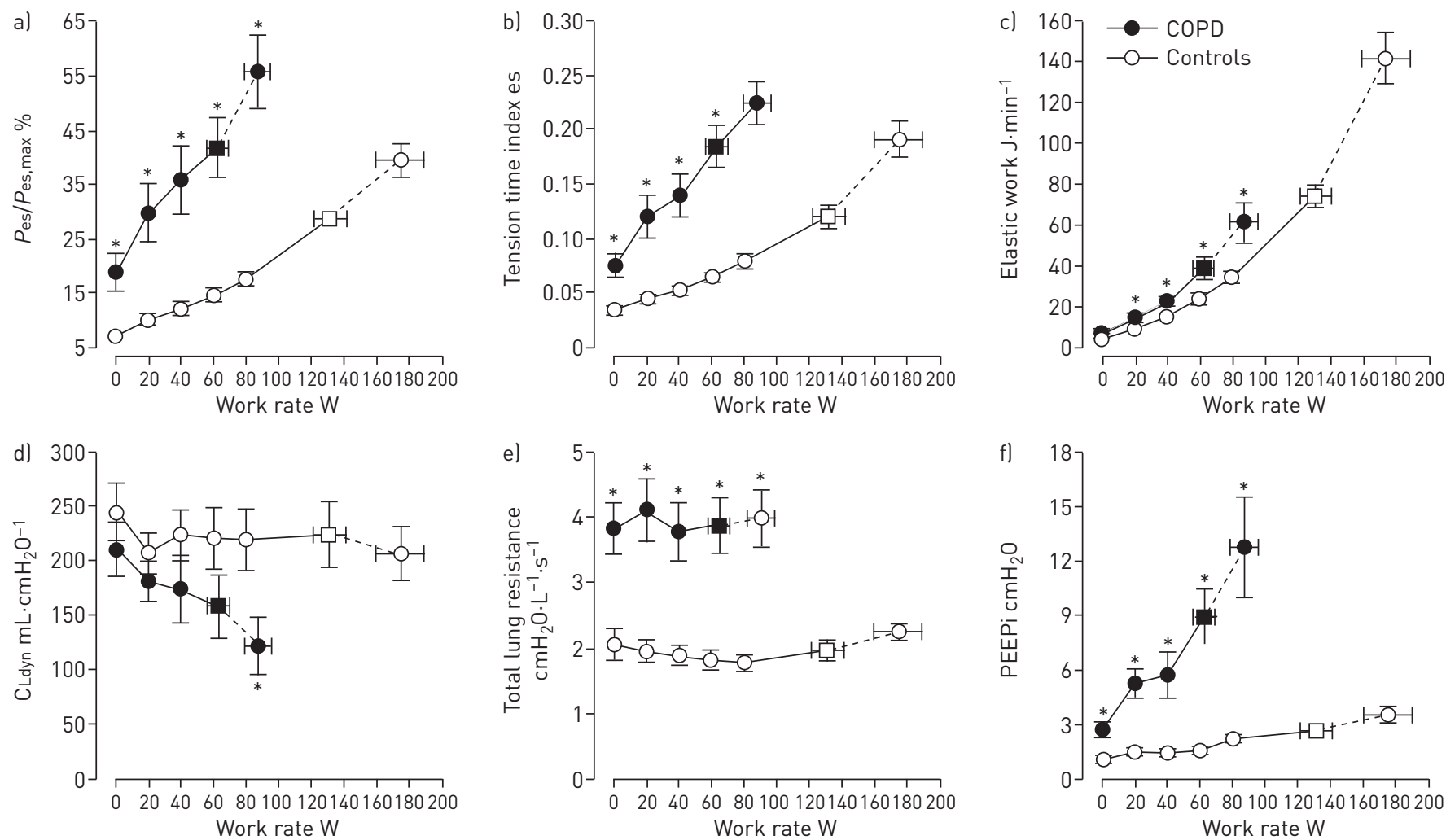

FIGURE 2 a-f) Respiratory mechanical measurements during incremental cycle exercise in patients with moderate chronic obstructive pulmonary disease (COPD) and age-matched healthy controls. Data are presented as mean \pm SEM. Square symbols represent tidal volume-ventilation inflection points. Pes: oesophageal pressure; Pes,max: maximal Pes; CLdyn: dynamic lung compliance; PEEPi: intrinsic positive end-expiratory pressure. *: p<0.05 COPD versus healthy controls at rest, at standardised work rates or at peak exercise. Reproduced and modified from [17] with permission.

drive in COPD is ultimately the consequence of increased chemostimulation and excessive mechanical loading, as well as functional weakness of the muscles of breathing, in highly variable combinations.

Increased reflex chemostimulation

Increased stimulation of central and peripheral chemoreceptors in COPD occurs as a result of: 1) alveolar ventilation/perfusion $\left(V^{\prime} \mathrm{A} / Q^{\prime}\right)$ abnormalities (decreased ventilatory efficiency, high $V^{\prime} \mathrm{A} / Q^{\prime}$ lung units and increased physiological dead space) [18-20]; 2) critical arterial oxygen $\left(\mathrm{O}_{2}\right)$ desaturation (low $V^{\prime} \mathrm{A} / Q^{\prime}$ lung units and reduced systemic mixed venous $\mathrm{O}_{2}$ in the blood) [21, 22]; and 3) increased acid-base disturbances (e.g. early metabolic acidosis) due to deconditioning [23, 24]. The negative haemodynamic consequences of hyperinflation may increase pulmonary vascular resistance and decrease left ventricular filling pressures [25]. The consequent impairment in cardiac output may reduce $\mathrm{O}_{2}$ delivery to the contracting peripheral muscles contributing to further increase afferent ventilatory stimuli (acidosis and ergo-receptor stimulation) [26-29].

Thus, increased reflex ventilatory stimulation may also arise from increased activation of ergo- and metabo-receptors in the active peripheral muscles [30], where the metabolic milieu is often acidic. Finally, increased intrinsic mechanical loading of the functionally weakened respiratory muscles also means that increased efferent motor drive is required to achieve a given force generation by these muscles [31, 32].

\section{Abnormal dynamic mechanics}

Increased respiratory motor drive and contractile respiratory muscle effort occur as a result of increased elastic loading (including increased inspiratory threshold loading due to the effect of intrinsic positive end-expiratory pressure (PEEP)), decreased dynamic lung compliance and increased resistive loading of the respiratory muscles (figure 2) [17,33-36]. Critical dynamic mechanical constraints are indicated by dynamic lung hyperinflation during exercise (i.e. the transient increase of end-expiratory lung volume (EELV) above the resting value) and by premature encroachment of end-inspiratory lung volume (EILV) on total lung capacity (TLC) (i.e. the attainment of a critically reduced inspiratory reserve volume (IRV)) [37, 38]. Thus, tidal volume $(V \mathrm{~T})$ becomes positioned close to TLC and the upper reaches of the S-shaped pressure-volume relationship of the relaxed respiratory system, where compliance is decreased and the inspiratory muscles are functionally weakened. This explains the blunted $V$ T response and relative tachypnoea in COPD compared 

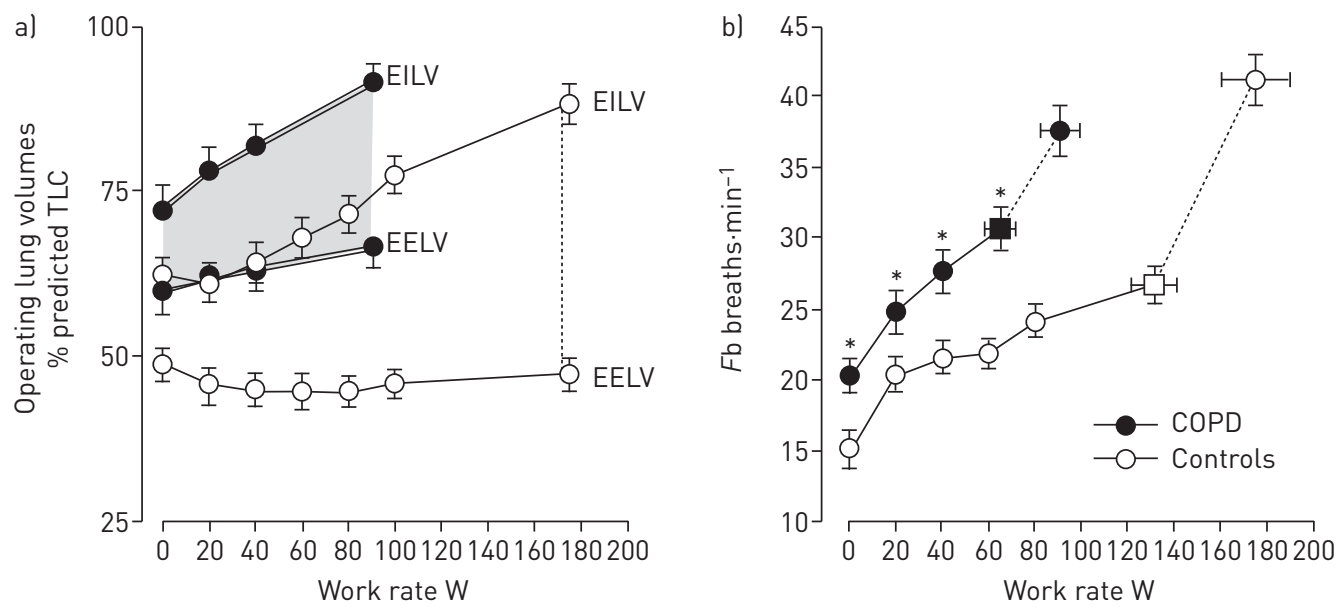

FIGURE 3 a) Operating lung volumes and b) breathing frequency $\left(F_{b}\right)$ during incremental cycle exercise in patients with moderate chronic obstructive pulmonary disease (COPD) and age-matched healthy controls. Data are presented as mean \pm SEM. Square symbols represent tidal volume-ventilation inflection points. TLC: total lung capacity; EILV: end-inspiratory lung volume; EELV: end-expiratory lung volume. *: p $<0.05$ COPD versus healthy controls at rest, at standardised work rates or at peak exercise. Reproduced and modified from [17] with permission.

with healthy controls. Increased breathing frequency and the attendant increased velocity of shortening of inspiratory muscles causes further functional weakness of the inspiratory muscles [39].

A simple noninvasive assessment of dynamic respiratory mechanics can be made by plotting operating lung volumes, derived from serial inspiratory capacity (IC) manoeuvres throughout exercise, and concomitant breathing pattern (figure 3) $[17,37,38]$. EELV can be calculated by subtracting IC from the pre-determined TLC; thus, change in IC reflects change in EELV on the assumption that TLC remains stable during rest and exercise [38]. The dynamic IRV is calculated as IC minus $V \mathrm{~T}$ and plotted at standardised work rates during the exercise test. The $V \mathrm{~T}$ plateau generally occurs when the $V \mathrm{~T} / \mathrm{IC}$ ratio is $\sim 0.7$ (or when IRV is $0.5-1.0 \mathrm{~L}$ ) regardless of disease severity [37].

Tidal flow-volume loop analysis with reference to the maximal flow-volume "capacity" envelope also provides important information about the mechanical reserves of the respiratory system [40, 41]. Flowvolume loop analysis provides a crude qualitative assessment of expiratory flow limitation, but nevertheless clearly exposes the prevailing dynamic mechanical constraints on volume expansion during progressive exercise (outlined earlier in this review) [40,41].

Although exercise limitation is undoubtedly multifactorial, multiple studies uniformly highlight that ventilatory factors are often the proximate limitation to exercise performance across the continuum of COPD [20, 33, 37, 42-45]. Furthermore, it is reasonable to surmise that attendant perceived respiratory discomfort is integral to the concept of ventilatory limitation in COPD [17, 45]. Moreover, it has now become clear that reliance on traditional estimates of breathing reserve (estimated maximal ventilatory capacity (MVC) minus peak minute ventilation $\left(V^{\prime} \mathrm{E}\right)$ ) can underestimate true ventilatory limitation indicated by premature attainment of critical respiratory mechanical constraints and accompanying intolerable dyspnoea at relatively low work rates $[45,46]$.

\section{Mechanisms of dyspnoea}

Sensory intensity of dyspnoea

Broadly speaking, dyspnoea during exercise reflects an imbalance between the increased demand to breathe and the ability to meet that demand [47]. Thus, the intensity of dyspnoea during exercise in COPD correlates closely with the following physiological ratios: ventilation as a fraction of MVC ( $V^{\prime} \mathrm{E} / \mathrm{MVC}$ ); respiratory effort relative to maximal effort as measured by oesophageal pressures (Pes/Pes,max); VT/IC or EILV/TLC; and inspiratory neural drive to the diaphragm relative to the maximum as measured by electromyography (EMGdi/EMGdi,max) (figure 4) [17, 33, 48-51]. Taken together, these studies suggest that the onset of perceived intensity of respiratory discomfort corresponds with a point during exercise where there is critical encroachment on reserves of ventilatory output, muscle force generation, $V \mathrm{~T}$ expansion and inspiratory neural drive to the diaphragm [17, 33, 48-51]. Although expiratory muscles are usually recruited during exercise in most patients with COPD, they do not mitigate the rise in EELV, the relatively early respiratory mechanical constraints or the attendant perceived inspiratory difficulty [52]. 
a)
$\bar{\Xi}$
$\frac{0}{0}$
$u$
0
0
0
$\cong$
0
0
0
0
01
0
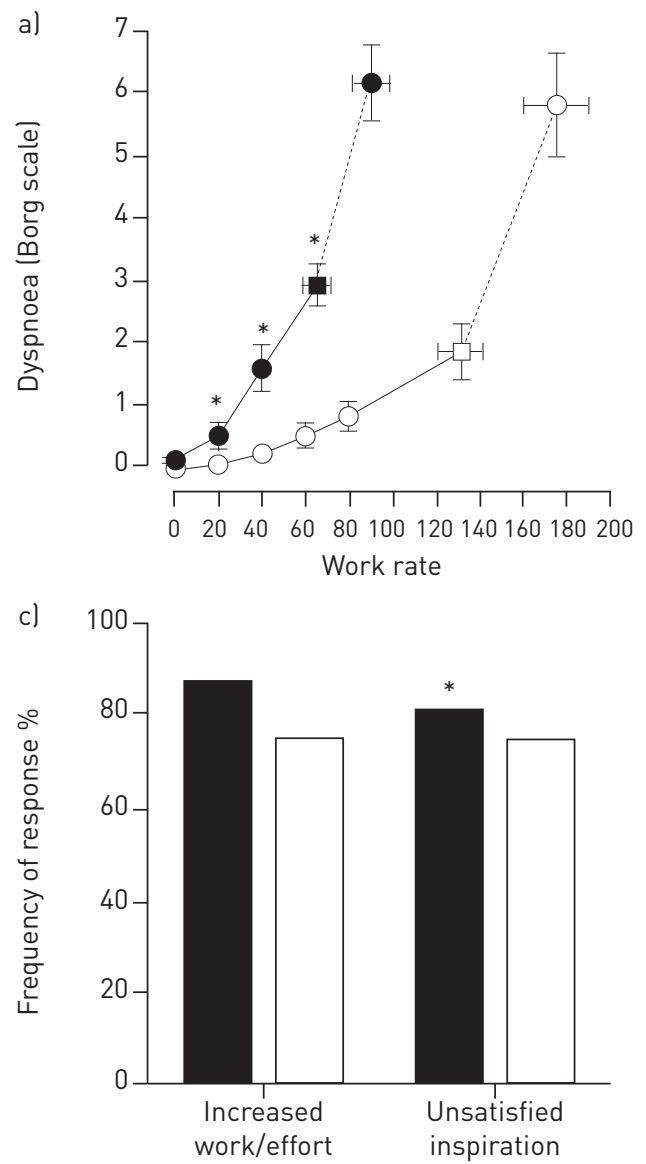
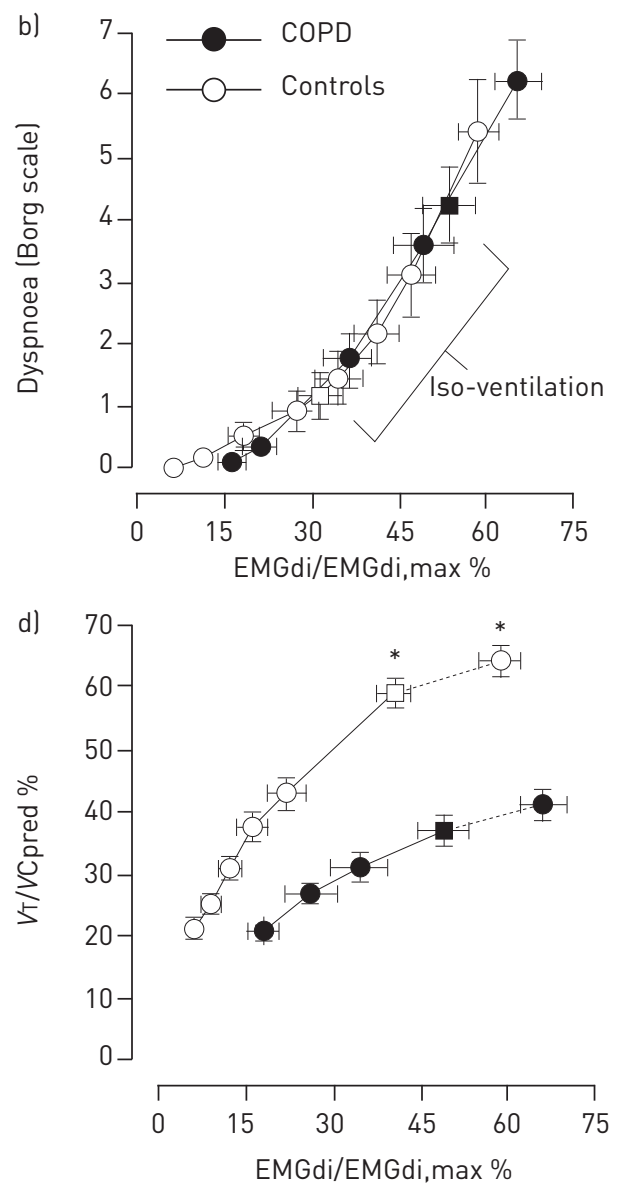

FIGURE 4 Exertional dyspnoea intensity is shown relative to a) work rate and b) diaphragm electromyography relative to maximum (EMGdi/EMGdi,max) during incremental cycle exercise in patients with moderate chronic obstructive pulmonary disease (COPD) and age-matched healthy controls. c) Selected qualitative dyspnoea descriptors at the end of incremental cycle exercise in patients with moderate COPD and age-matched healthy controls. d) The relationship between tidal volume $\left(V_{T}\right)$ as a function of predicted vital capacity (VCpred) and EMGdi/EMGdi,max. Square symbols represent the tidal volume-ventilation inflection points in panels al and d) and the point at the highest equivalent ventilation $\left(50 \mathrm{~L} \cdot \mathrm{min}^{-1}\right)$ in panel b). Data are presented as mean \pm SEM. *: $p<0.05$ COPD versus healthy controls at rest, at standardised work rates or at peak exercise. Reproduced and modified from [17] with permission.

There is corroborative evidence that intensity of breathlessness rises with increasing tidal inspiratory efferent neural activity from bulbo-pontine and cortical motor centres in the brain relative to the maximum possible neural activation (indirectly represented by physiological ratios outlined above) [17, 33, 48]. It is further postulated that attendant increased central corollary discharge to the somato-sensory cortex, where unpleasant respiratory sensations are consciously perceived, is a final common sensory pathway [53, 54].

\section{Quality of dyspnoea}

It is postulated that the main qualitative dimension of breathlessness in COPD (i.e. "unsatisfied inspiration") has its neurophysiological basis in the widening dissociation between increasing efferent central neural drive and the blunted respiratory muscular/mechanical response of the compromised respiratory system (i.e. neuromechanical dissociation), due partly to the combined effects of resting and dynamic lung hyperinflation (figure 4) [17, 55-57]. We have demonstrated that the descriptor "unsatisfied inspiration" becomes more frequently selected than the descriptor of increased "work/effort" after the $V$ T plateau $[17,57]$, where neuromechanical dissociation increases more abruptly. In line with this theory, it has been repeatedly shown that external imposition of mechanical loads to impede respiration in healthy volunteers in the face of constant or increasing chemostimulation reliably provokes respiratory sensations such as "air hunger" akin to "unsatisfied inspiration" [58-61]. Although definitive experimental verification is lacking, it is also entirely plausible that afferent inputs from the lungs to the somato-sensory cortex (via the vagus nerve) or from a multitude of mechanoreceptors in the respiratory muscle and chest wall (via spinal pathways) can directly induce unpleasant respiratory sensations that shape the clinical 
expression of dyspnoea [62]. There is new information that endogenous opiate production can further modulate multidimensional dyspnoea in patients with COPD [63].

\section{The affective dimension}

Respiratory discomfort beyond a certain threshold evokes an emotive or affective response such as anxiety, fear, panic or distress. The threshold for affective distress probably varies between individuals and is ultimately thought to be linked to increased activation of limbic and paralimbic "flight or fight" centres in the brain and associated over-activation of the sympathetic nervous system [64-70].

\section{Measuring dyspnoea during CPET}

Prior to CPET, and in addition to a careful history (as outlined earlier in this review), it is important to ascertain the impact of dyspnoea on the patient's daily living using simple magnitude of task (e.g. MRC dyspnoea scale) or multidimensional questionnaire (Baseline Dyspnoea Index) [71]. An assessment of the patient's habitual physical activity level is helpful to ascertain if skeletal muscle deconditioning is potentially contributing to low cardio-respiratory fitness and associated higher ventilatory demand [72]. Full pulmonary function tests (spirometry, lung volume components including IC, diffusing capacity of the lung and resting arterial $\mathrm{O}_{2}$ saturation) are also a prerequisite. Documentation of comorbidities potentially associated with exertional dyspnoea (obesity [73-76], cardio-circulatory disorders [77-79], anaemia, etc.) is also essential for proper CPET interpretation.

Intensity of dyspnoea during exercise can be measured using one of two validated scales: the modified 10-point Borg scale [80] or a visual analogue scale [81]. In practice, the 10-point Borg scale, a category scale with ratio properties, is more commonly used and easy to administer in clinical and research settings. It has been shown to be reliable, being both reproducible and responsive in COPD populations [82]. Care must be taken to precisely clarify the respiratory sensation that the patient is being asked to quantify (e.g. breathing discomfort, breathing effort or unpleasantness of breathing). The sensation in question should be anchored to the numeric extremes of the scale: $0=$ no breathing discomfort and $10=$ the strongest intensity of breathing discomfort that the patient has experienced or can imagine [80]. Before CPET, the patient should be thoroughly familiarised with the range of numerals and the associated word descriptors. The patient is then asked to rate the strength of intensity of breathing discomfort every 2 min throughout exercise by pointing to the appropriate numeral. Borg dyspnoea ratings are then plotted as a function of increasing oxygen uptake $\left(V^{\prime} \mathrm{O}_{2}\right)$, work rate or $V^{\prime} \mathrm{E}$ and compared with reference values from a healthy age- and sex-matched population, preferably developed in the same exercise laboratory [83].

Measuring the affective component of dyspnoea during CPET remains challenging and there is currently no consensus as to the best approach. Preliminary studies have measured dyspnoea-related anxiety using the 10-point Borg scale during CPET and show that this is responsive to interventions such as pulmonary rehabilitation $[84,85]$. In these studies patients with COPD could differentiate (and separately rank) sensory intensity and affective domains of dyspnoea.

There is debate about the best exercise modality (treadmill or cycle exercise) for the purpose of clinical assessment of exertional dyspnoea [86-89]. Within individuals with COPD, dyspnoea/work rate plots and dyspnoea/ $V^{\prime} \mathrm{E}$ are similar during treadmill and cycle exercise when the increase in incremental work rate is matched $[73,90]$. Moreover, the relative increase in perceived leg effort ratings at higher exercise intensities during cycle exercise, compared with treadmill walking, does not influence Borg/ $V^{\prime} \mathrm{E}$ or Borg/work rate slopes of dyspnoea intensity $[73,90]$. Interestingly, the earlier metabolic acidosis and corresponding rise in $V^{\prime} \mathrm{E}$ during cycle exercise is associated with an earlier rise in dyspnoea than during treadmill walking, when work rate increases are matched across modalities [73, 86, 88]. When abnormalities of pulmonary gas exchange are suspected as a source of increased ventilatory stimulation and exertional dyspnoea, treadmill testing is likely to be more sensitive than cycling since arterial blood gas perturbations are exaggerated for a given $V^{\prime} \mathrm{O}_{2}$ with weight-bearing walking compared with cycling $[73,86,88]$.

\section{CPET interpretation: panel displays}

Since evaluation of exertional dyspnoea is the focus of the current review, we propose an ordered presentation of perceptual and physiological responses as presented, in part, in figure 5 [45]. 1) perceptual responses: dyspnoea (Borg) ratings as a function of work rate (and/or $\left.V^{\prime} \mathrm{E}\right) ; 2$ ) ventilatory control: $V^{\prime} \mathrm{E} /$ work rate, $V^{\prime} \mathrm{O}_{2} /$ work rate, ventilatory equivalent for carbon dioxide $\left(V^{\prime} \mathrm{E} / V^{\prime} \mathrm{CO}_{2}\right) /$ work rate, $\mathrm{O}_{2}$ saturation/work rate, end-tidal $\mathrm{CO}_{2}$ /work rate and ventilatory thresholds (e.g. carbon dioxide output $\left(V^{\prime} \mathrm{CO}_{2}\right) / V^{\prime} \mathrm{O}_{2}$ inflection method, a measure of acid-base disturbance); 3) dynamic respiratory mechanics: change in IC, IRV, $V \mathrm{~T}$ and breathing frequency, all as a function of increasing work rate (or $V^{\prime} \mathrm{E}$ ); and 4) cardio-circulatory responses: heart rate relative to predicted peak heart rate and $\mathrm{O}_{2}$ pulse $[17,20,33,37,44,45]$. 

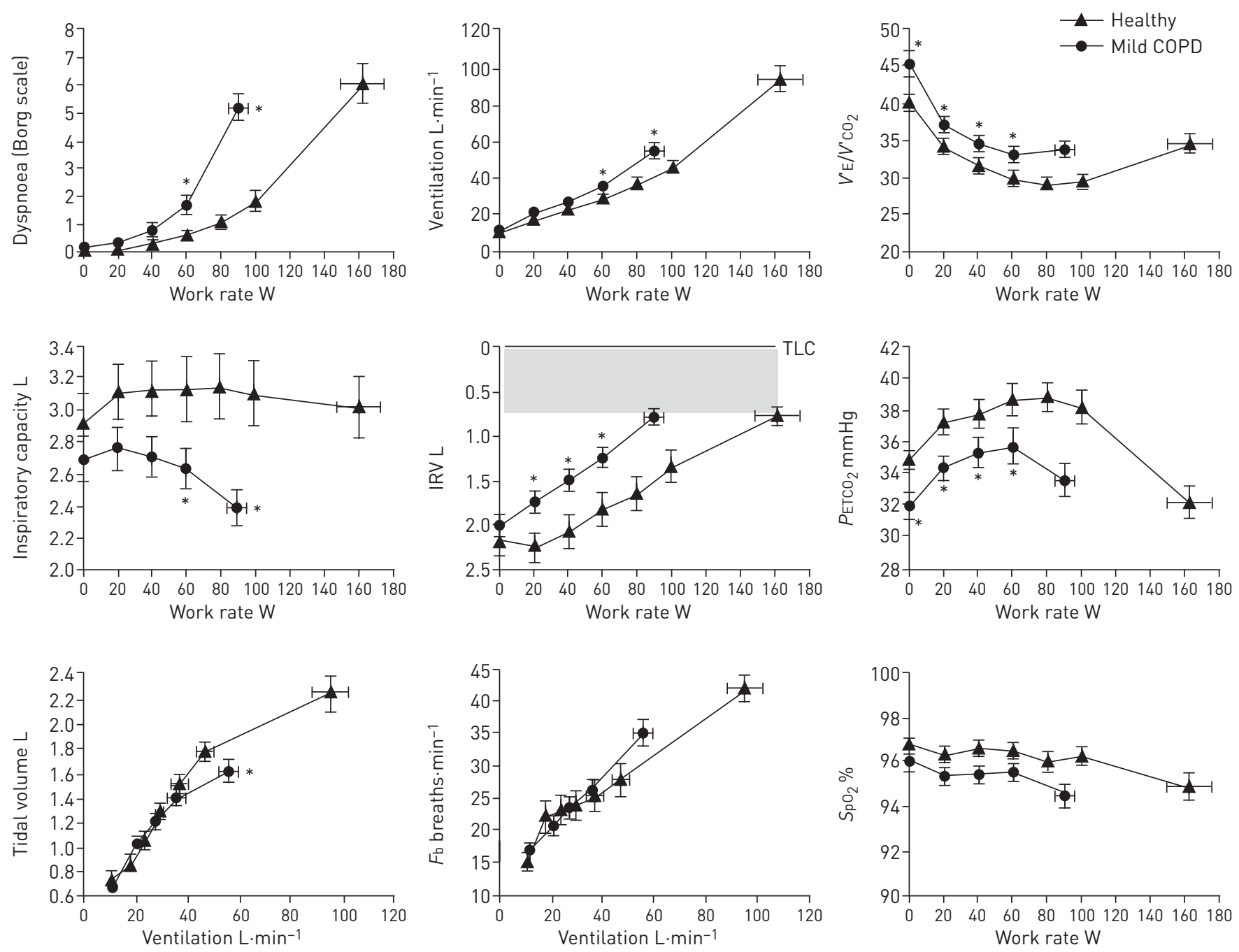

FIGURE 5 Proposed panel displays during interpretation of an incremental exercise test. Data showing selected perceptual, ventilatory control and dynamic respiratory mechanics to incremental cycle exercise in patients with mild chronic obstructive pulmonary disease (COPD) and age-matched healthy controls. Data are presented as mean $\pm \mathrm{SEM} . V^{\prime} \mathrm{E} / V^{\prime} \mathrm{CO}_{2}$ : ventilatory equivalent for carbon dioxide; IRV: inspiratory reserve volume; Fb: breathing frequency; $P \mathrm{ETCO}_{2}$ : partial pressure of end-tidal carbon dioxide; $\mathrm{SpO}_{2}$ : arterial oxygen saturation measured by pulse oximetry; TLC: total lung capacity. *: p $<0.05$ mild COPD versus healthy controls at rest, at standardised work rates or at peak exercise. Reproduced from [45] with permission.

This simple format allows the clinician to evaluate the magnitude of perceived intensity of dyspnoea and exercise intolerance (peak work rate or $V^{\prime} \mathrm{O}_{2}$ achieved) in the individual and then to identify potential contributory factors. These include: increased ventilatory demand or drive and its underlying cause(s) (increased ventilatory inefficiency, critical hypoxaemia or early ventilatory threshold), or reduced mechanical/metabolic efficiency, as occurs in obesity (parallel upward shift of $V^{\prime} \mathrm{O}_{2}$ /work rate relationship); and severe mechanical constraints (increase in EELV, rapid reduction of IRV to its minimal value, early $V \mathrm{~T}$ plateau/ventilation and corresponding onset of tachypnoea) $[17,20,33,37,44,45]$. Cardio-circulatory responses are often nonspecific, but may demonstrate relative tachycardia, reduced $\mathrm{O}_{2}$ pulse, reduced $V^{\prime} \mathrm{O}_{2} /$ work rate relationship and early ventilatory threshold that suggest the presence of either skeletal muscle deconditioning or reduced cardiac output [91, 92]. 12-lead electrocardiography, normally incorporated into CPET, can uncover hitherto undiagnosed ischaemic heart disease.

The $V^{\prime} \mathrm{E}-V^{\prime} \mathrm{CO}_{2}$ relationship is invariably helpful for the clinical interpretation of CPET in patients with COPD. This relationship has been analysed either in the ventilatory equivalent for $\mathrm{CO}_{2}\left(V^{\prime} \mathrm{E} / V^{\prime} \mathrm{CO}_{2}\right.$ ratio) versus work rate plot (figure 5) or in the $V^{\prime} \mathrm{E}$ versus $V^{\prime} \mathrm{CO}_{2}$ plot. During mild-to-moderate exercise, $V^{\prime} \mathrm{E} / V^{\prime} \mathrm{CO}_{2}$ decreases in tandem with the physiological dead space/ $V$ T ratio [93]. The lowest (nadir) $V^{\prime} \mathrm{E} / V^{\prime} \mathrm{CO}_{2}$ is reached just before $V^{\prime} \mathrm{E}$ starts to compensate for lactic acidosis thereby providing an indicator of the "wasted" ventilation (ventilatory inefficiency) [94]. It should be noted, however, that the $V^{\prime} \mathrm{E} / V^{\prime} \mathrm{CO}_{2}$ response contour depends on how $V^{\prime} \mathrm{E}$ changes in relation to $V^{\prime} \mathrm{CO}_{2}$ taking into consideration its starting point. The former is reflected by the slope of the $V^{\prime} \mathrm{E}$ versus $V^{\prime} \mathrm{CO}_{2}$ regression line and the latter by its intercept, i.e. $V^{\prime} \mathrm{E}$ when 
$V^{\prime} \mathrm{CO}_{2}=0$. In other words, the $V^{\prime} \mathrm{E} / V^{\prime} \mathrm{CO}_{2}$ nadir equals the slope plus intercept [95]. As discussed in the following section of this review, COPD severity strongly influences the different metrics of ventilatory inefficiency (nadir, slope and intercept) [19, 96, 97].

This approach not only allows an objective assessment of severity of activity-related dyspnoea in the patient but will also often reveal abnormal physiological responses, which cannot easily be predicted from a thorough history and/or the results of resting pulmonary function tests [12]. These include: the presence of critical dynamic mechanical constraints of the respiratory system, high ventilatory demand at low exercise intensities indicating a preponderance of lung units with high $V^{\prime} \mathrm{A} / Q^{\prime}$ ratios or alveolar hyperventilation, significant arterial $\mathrm{O}_{2}$ desaturation, or a pattern of responses that suggest decreased cardio-respiratory fitness $[17,20,33$, $37,44,45]$. All of these factors, singly or in combination, can help explain the underlying dyspnoea and their discovery during CPET helps facilitate a more personalised management strategy for the patient with COPD.

\section{Increasing exertional dyspnoea with disease progression}

\section{CPET in mild COPD}

CPET is particularly useful for evaluation of mechanisms of exertional dyspnoea in individuals in whom this symptom seems disproportionate to the degree of respiratory impairment as assessed by simple pulmonary function tests (figure 5) [45]. In this context, recent epidemiological studies have confirmed that activity-related dyspnoea and activity restriction are present in many smokers with normal spirometry [98-100]. A series of studies have recently exposed heterogeneous dynamic physiological abnormalities during exercise in such symptomatic smokers without spirometrically defined COPD [48, 98]. The dominant abnormalities in patients with spirometrically determined mild COPD include: 1) increased inspiratory neural drive to breathe, secondary to measured high physiological dead space as indirectly assessed by $V^{\prime} \mathrm{E} / V^{\prime} \mathrm{CO}_{2}$ (nadir and slope); and 2) increased pulmonary gas trapping due to the combined effects of peripheral airway disease (expiratory flow limitation) and increased ventilatory demand, which together force earlier critical mechanical constraints and higher exertional dyspnoea ratings than in healthy controls [20,33,44, 45, 101]. Thus, relatively preserved mechanical reserves during the early phases of exercise allows increased physiological dead space to be readily translated into a higher $V^{\prime} \mathrm{E}-V^{\prime} \mathrm{CO}_{2}$ relationship in patients with mild $\mathrm{COPD}$, i.e. higher $V^{\prime} \mathrm{E} / V^{\prime} \mathrm{CO}_{2}$ nadir and steeper $V^{\prime} \mathrm{E}-V^{\prime} \mathrm{CO}_{2}$ slope compared with healthy controls (figure 6) [19].

\section{CPET in moderate-to-severe COPD}

In more advanced COPD, the same physiological derangements apply as in mild COPD but occur at significantly lower $V^{\prime} \mathrm{E}$ and work rate. Inspiratory neural drive is substantially greater at lower exercise intensities than in patients with milder COPD reflecting worsening pulmonary gas exchange and mechanical constraints, in various combinations (figure 1) [17, 19, 37]. Increased drive in more advanced COPD is compounded in many patients by negative effects of low ventilatory thresholds (and metabolic acidosis) secondary to deconditioning and, in some cases, critical arterial $\mathrm{O}_{2}$ desaturation (arterial $\mathrm{O}_{2}$ tension $<60 \mathrm{mmHg}$ or $<8 \mathrm{kPa}$ ). It is noteworthy that, in contrast to mild $\mathrm{COPD}, V^{\prime} \mathrm{E} / V^{\prime} \mathrm{CO}_{2}$ (nadir and slope) is a less reliable reflection of $V^{\prime} \mathrm{A} / \mathrm{Q}^{\prime}$ abnormalities in advanced COPD where mechanical constraints blunt the $V^{\prime} E$ response and underestimate the magnitude of the prevailing inspiratory neural drive [19]. Progressive reduction of resting IC (as resting lung hyperinflation increases) with disease progression helps explain the ever-diminishing operating limits for $V \mathrm{~T}$ expansion and progressively earlier attainment of a minimal IRV during exercise (figure 7) [37]. The point at which $V$ T expands to reach a critical minimal IRV, the point where neuromechanical dissociation begins, is an important mechanical event during exercise and marks the threshold beyond which dyspnoea intensity rises sharply to reach intolerable levels (figure 8) [37, 55]. The lower the resting IC, the earlier in exercise this threshold is reached. Similarly, the progressively higher dyspnoea $/ V^{\prime} \mathrm{E}$ slopes as the disease advances are in large part explained by the worsening dynamic respiratory mechanics and muscle function described above.

It is noteworthy that, in contrast to mild COPD, mechanical constraints blunt the dynamic changes in $V^{\prime} \mathrm{E}$ increases in more advanced COPD. Thus, despite the progression of "wasted" ventilation, the slope decreases as the disease evolves [19, 96, 97]. Concomitant increases in intercept, however, frequently uncover the presence of ventilatory abnormalities leading to a high nadir (slope+intercept) in most moderate-to-severe COPD patients (figure 6) [19]. Some patients with end-stage, very severe COPD in whom the nadir is pronouncedly reduced and the $\mathrm{CO}_{2}$ set-point increased may present with normal-to-low nadirs [102]. As a corollary, $V^{\prime} \mathrm{E} / V^{\prime} \mathrm{CO}_{2}$ (nadir and slope) is a less reliable reflection of $V^{\prime} \mathrm{A} / Q^{\prime}$ abnormalities in advanced COPD where it underestimates the prevailing inspiratory neural drive [19].

\section{Evaluation of therapeutic interventions using CPET}

Based on our current understanding of the pathogenesis of activity-related dyspnoea, we can attempt to strategically intervene to treat this distressing symptom on an individual patient basis. The main goals are to: 1) improve respiratory mechanics and muscle function; 2) reduce the increased central neural drive; 

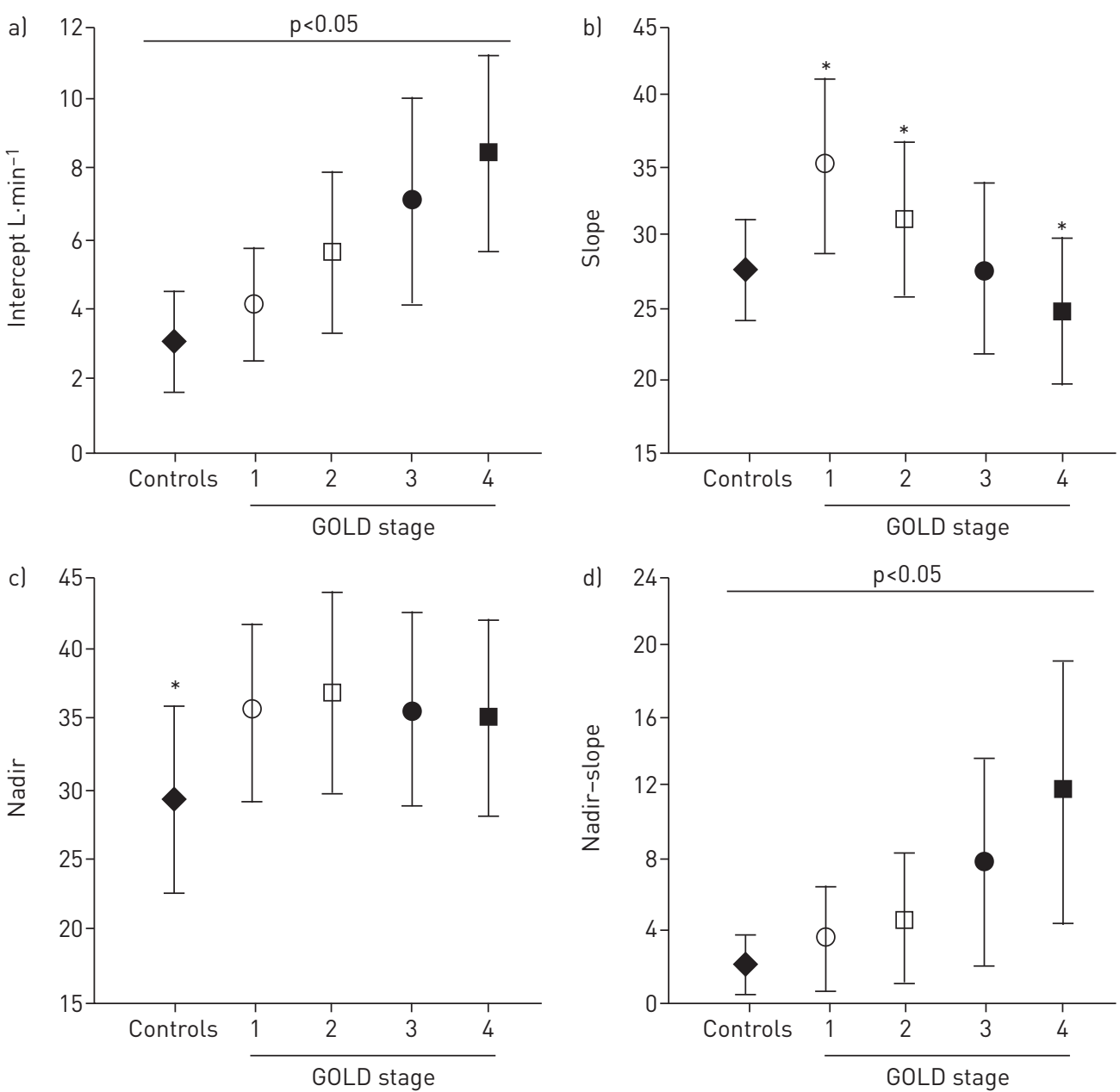

FIGURE 6 Effects of chronic obstructive pulmonary disease (COPD) severity on different parameters of ventilatory inefficiency during incremental cardiopulmonary exercise testing (CPET). a) Minute ventilation ( $\left.V^{\prime} E\right)$-carbon dioxide output $\left(V^{\prime} \mathrm{CO}_{2}\right)$ intercept increased and b) $V^{\prime} \mathrm{E}-V^{\prime} \mathrm{CO}_{2}$ slope diminished as the disease progressed from Global Initiative for Chronic Obstructive Lung Disease (GOLD) stages 1-4. c) As the $V^{\prime} E / V^{\prime} \mathrm{CO}_{2}$ nadir depends on both slope and intercept, it remained elevated (compared with controls) across disease stages. d) Increasing nadir-slope differences from GOLD stages 1-4 reflects the impact of a progressively higher intercept. *: $p<0.05$ COPD versus controls (panel b) or controls versus all COPD groups (panel c). Reproduced from [19] with permission.

and 3) address the affective component of dyspnoea. Combined interventions which impact all three of these goals are likely to have the greatest effect on dyspnoea alleviation during exercise [103]. For the purpose of evaluating the efficacy of various interventions in relieving activity-related dyspnoea in clinical or research settings, a constant work rate exercise protocol set at a fixed fraction of a pre-established peak work rate (e.g. $60-80 \%)$ is preferable [104]. This is justified on the grounds that any beneficial changes in lung mechanics and dyspnoea are more readily translated into increases in time to exercise intolerance (endurance) than changes in maximal exercise capacity [105]. Moreover, the ability to complete a given task is arguably more relevant to daily life than reaching greater levels of exertion, i.e. the constant work rate holds greater external validity compared with incremental CPET [104].

\section{Improving mechanics}

Bronchodilators of all classes and duration of action have consistently been shown to decrease lung hyperinflation, with reciprocal increases in resting IC in patients with COPD [103, 106-120]. By increasing resting IC, bronchodilators also increase the available IRV and thereby delay the onset of critical respiratory-mechanical constraints on $V$ T expansion during exercise $[55,103,106,120]$. Thus, throughout exercise, less central neural drive and respiratory muscle effort is required to achieve greater $V \mathrm{~T}$ expansion: neuromechanical dissociation is partially reversed, onset of intolerable dyspnoea is delayed and exercise tolerance is improved $[55,120]$. Both classes of inhaled bronchodilators ( $\beta_{2}$-agonists and muscarinic antagonists) have been shown to increase the resting IC in patients with COPD by $\sim 0.2-0.4 \mathrm{~L}$ or $\sim 10-15 \%$ $[103,106,112-114,116]$. Increases in cycle exercise endurance time in response to bronchodilator therapy 

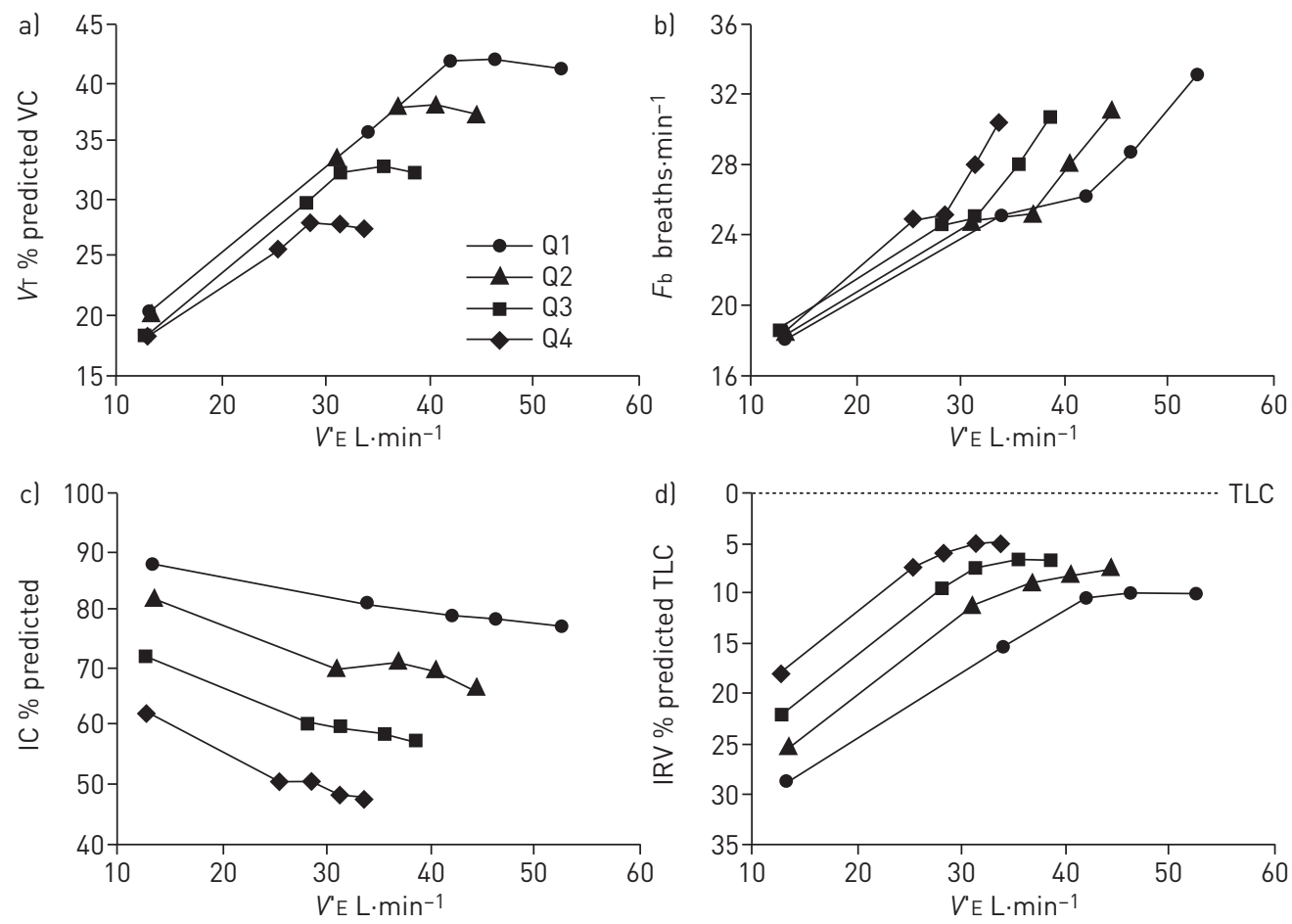

FIGURE 7 a) Tidal volume (VT) (presented as \% predicted of vital capacity (VC)), b) breathing frequency (Fb), c) dynamic inspiratory capacity (IC) and d) inspiratory reserve volume (IRV) (presented as \% predicted of total lung capacity (TLC)) are shown plotted against minute ventilation ( $V^{\prime} E$ ) in four disease severity quartiles based on forced expiratory volume in $1 \mathrm{~s} \%$ predicted during constant work rate exercise. Note the clear inflection (plateau) in the $V_{T} / V^{\prime} E$ relationship which coincides with a simultaneous inflection in the IRV. After this point, further increases in $V^{\prime} E$ are accomplished by accelerating $F$ b. Data are presented as mean values at steady-state rest, isotime (i.e. $2 \mathrm{~min}, 4 \mathrm{~min}$ ), the $V_{T} / V^{\prime} E$ inflection point and peak exercise. Reproduced from [37] with permission.

are of the order of $20 \%$, on average $[103,106,114,115,121]$. Such increases in cycling endurance time are typically within the range that is thought to be clinically important, i.e. about $100 \mathrm{~s}$.

\section{Reducing central respiratory drive}

Our ability to reduce the increased central neural drive during exercise is limited since the proximate source is often increased chemostimulation as a result of $V^{\prime} \mathrm{A} / \mathrm{Q}^{\prime}$ abnormalities (compromised $\mathrm{CO}_{2}$ elimination), which are often irreversible. In some individuals with more moderate COPD who are sufficiently motivated, multi-modality exercise training can result in a delay in the rise of metabolic $\mathrm{CO}_{2}$ output (by improving aerobic capacity) and consequently, a delay in the rise of central neural drive, the rate of dynamic hyperinflation and the onset of intolerable dyspnoea $[85,122-125]$. In selected individuals, supplemental $\mathrm{O}_{2}[103,126-129]$ or opioid
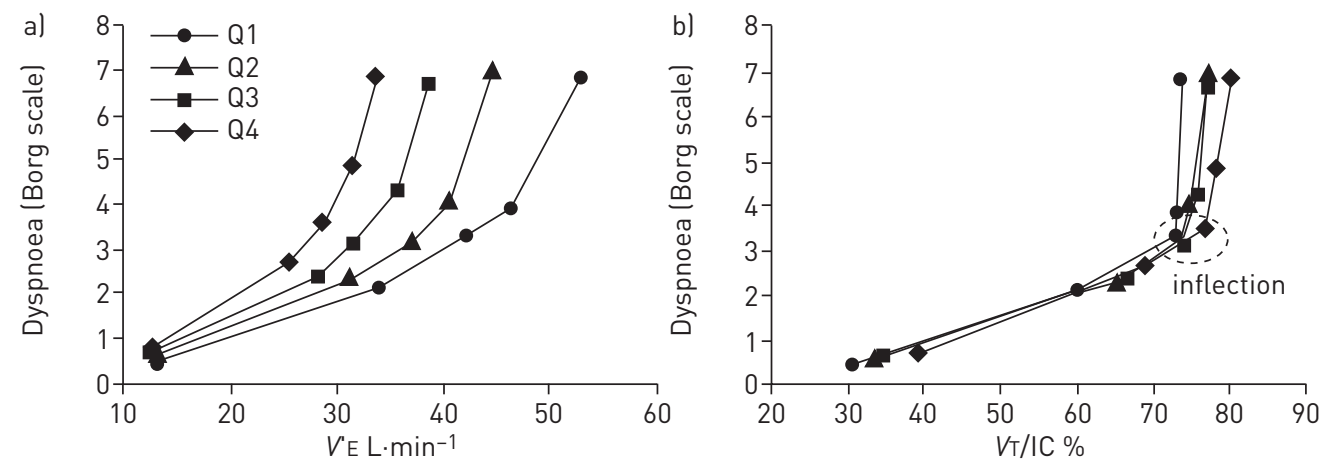

FIGURE 8 Interrelationships are shown between exertional dyspnoea intensity and a) minute ventilation ( $V^{\prime}$ E) and b) the tidal volume (VT)/inspiratory capacity (IC) ratio in four disease severity quartiles based on forced expiratory volume in $1 \mathrm{~s} \%$ predicted during constant work rate exercise. After the $\mathrm{V}$ T/IC ratio plateaus li.e. the $V T$ inflection point) dyspnoea rises steeply to intolerable levels. There is a progressive separation of dyspnoea/ $V^{\prime} E$ plots with worsening quartile. Data are presented as mean values at steady-state rest, isotime li.e. 2 min, $4 \mathrm{~min}$ ), the $V \mathrm{~T} / V^{\prime} E$ inflection point and peak exercise. Reproduced from [37] with permission. 
medication $[63,130-135]$, which directly or indirectly reduces central respiratory drive, can ameliorate dyspnoea during physical activity and improve exercise endurance. Reduced neural drive following these interventions usually manifests as reduced breathing frequency (and increased expiratory time) often with an attendant decrease in the rate of dynamic hyperinflation $[108,113,126,128,131]$. Supplemental $\mathrm{O}_{2}$ can also improve $\mathrm{O}_{2}$ delivery and utilisation at the peripheral muscle level thereby delaying onset of metabolic acidosis and the attendant rise in ventilatory stimulation [126, 136-140]. The most recent meta-analysis on the efficacy of low-dose opiates found that dyspnoea was reduced (eight studies with 118 participants): standardised mean difference in favour of intervention of -0.34 ( $95 \%$ CI $-0.58--0.10)$ [132]. However, it failed to demonstrate a significant effect on exercise capacity (standardised mean difference of 0.06 (95\% CI -0.15-0.28)) [132].

In patients in whom anxiety is a major feature, a trial of anxiolytic medication and psychological counselling, usually within the framework of pulmonary rehabilitation [84, 85], can help address this important affective aspect of exertional dyspnoea [141, 142].

\section{Conclusion}

Activity-related dyspnoea affects a great many patients with COPD worldwide. Our understanding of the underlying mechanisms continues to grow and a central factor in causation seems to be increased efferent neural drive to the inspiratory muscles, originating in bulbo-pontine and cortical motor centres of the brain. Inspiratory drive is amplified in patients with COPD, compared with healthy individuals, because of relatively increased chemostimulation and abnormal dynamic respiratory mechanics and muscle function that collectively reflect the pathophysiology of the underlying disease. Progressive worsening of activity-related dyspnoea and exercise tolerance as COPD severity increases is fundamentally explained by progressively increasing central respiratory drive and neuromechanical dissociation of the respiratory system. CPET offers the clinician a unique opportunity to evaluate the severity of dyspnoea and its underlying mechanisms on an individual patient basis, and is particularly useful when symptom intensity seems disproportionate to the results of resting pulmonary function tests. In fact, recent studies provide compelling evidence that persistent respiratory symptoms and exercise intolerance are poorly correlated with spirometry and underline the importance of additional clinical evaluation of respiratory impairment. In this context, CPET can provide a comprehensive physiological assessment of the dyspnoeic COPD patient and is likely to have expanded clinical utility in the future. A simple ordered approach which examines symptom intensity, "noninvasive" ventilatory control parameters and dynamic respiratory mechanics during a standardised incremental exercise test to tolerance can identify mechanisms underlying perceived respiratory discomfort that are amenable to targeted treatment.

\section{References}

1 Buist AS, McBurnie MA, Vollmer WM, et al. International variation in the prevalence of COPD (the BOLD Study): a population-based prevalence study. Lancet 2007; 370: 741-750.

2 Raghavan N, Lam Y-M, Webb KA, et al. Components of the COPD Assessment Test (CAT) associated with a diagnosis of COPD in a random population sample. COPD 2012; 9: 175-183.

3 Parshall MB, Schwartzstein RM, Adams L, et al. An official American Thoracic Society statement: update on the mechanisms, assessment, and management of dyspnea. Am J Respir Crit Care Med 2012; 185: 435-452.

4 Nishimura K, Izumi T, Tsukino M, et al. Dyspnea is a better predictor of 5-year survival than airway obstruction in patients with COPD. Chest 2002; 121: 1434-1440.

5 Waschki B, Kirsten A, Holz O, et al. Physical activity is the strongest predictor of all-cause mortality in patients with COPD: a prospective cohort study. Chest 2011; 140: 331-342.

6 Oga $T$, Nishimura $K$, Tsukino $M$, et al. Analysis of the factors related to mortality in chronic obstructive pulmonary disease: role of exercise capacity and health status. Am J Respir Crit Care Med 2003; 167: 544-549.

7 Pinto-Plata VM, Cote C, Cabral H, et al. The 6-min walk distance: change over time and value as a predictor of survival in severe COPD. Eur Respir J 2004; 23: 28-33.

8 O'Donnell DE, Hernandez P, Kaplan A, et al. Canadian Thoracic Society recommendations for management of chronic obstructive pulmonary disease - 2008 update - highlights for primary care. Can Respir J 2008; 15: Suppl. A, 1A-8A.

9 Global Initiative for Chronic Obstructive Lung Disease. Global Strategy for the Diagnosis, Management and Prevention of COPD, 2016. http://www.goldcopd.org Date last accessed: March 15, 2016.

10 Qaseem A, Wilt TJ, Weinberger SE, et al. Diagnosis and management of stable chronic obstructive pulmonary disease: a clinical practice guideline update from the American College of Physicians, American College of Chest Physicians, American Thoracic Society, and European Respiratory Society. Ann Intern Med 2011; 155: 179-191.

11 Soumagne T, Laveneziana P, Veil-Picard M, et al. Asymptomatic subjects with airway obstruction have significant impairment at exercise. Thorax 2016; in press [DOI: 10.1136/thoraxjnl-2015-207953].

12 Oga T, Tsukino M, Hajiro T, et al. Analysis of longitudinal changes in dyspnea of patients with chronic obstructive pulmonary disease: an observational study. Respir Res 2012; 13: 85.

13 Lopes AJ, Mafort TT. Correlations between small airway function, ventilation distribution, and functional exercise capacity in COPD patients. Lung 2014; 192: 653-659.

14 Mahler DA, O'Donnell DE. Recent advances in dyspnea. Chest 2015; 147: 232-241.

15 Mahler DA, Selecky PA, Harrod CG, et al. American College of Chest Physicians consensus statement on the management of dyspnea in patients with advanced lung or heart disease. Chest 2010; 137: 674-691.

16 O’Donnell DE, Banzett RB, Carrieri-Kohlman V, et al. Pathophysiology of dyspnea in chronic obstructive pulmonary disease: a roundtable. Proc Am Thorac Soc 2007; 4: 145-168. 
Faisal A, Alghamdi BJ, Ciavaglia CE, et al. Common mechanisms of dyspnea in chronic interstitial and obstructive lung disorders. Am J Respir Crit Care Med 2016; 193: 299-309.

Caviedes IR, Delgado I, Soto R. Ventilatory inefficiency as a limiting factor for exercise in patients with COPD. Respir Care 2012; 57: 583-589.

Neder JA, Arbex FF, Alencar MC, et al. Exercise ventilatory inefficiency in mild to end-stage COPD. Eur Respir J 2015; 45: 377-387.

Elbehairy AF, Ciavaglia CE, Webb KA, et al. Pulmonary gas exchange abnormalities in mild chronic obstructive pulmonary disease. Implications for dyspnea and exercise intolerance. Am J Respir Crit Care Med 2015; 191: 1384-1394.

Moreira MÂ, Medeiros GA, Boeno FP, et al. Oxygen desaturation during the six-minute walk test in COPD patients. J Bras Pneumol 2014; 40: 222-228.

Andrianopoulos V, Franssen FM, Peeters JP, et al. Exercise-induced oxygen desaturation in COPD patients without resting hypoxemia. Respir Physiol Neurobiol 2014; 190: 40-46.

Patessio A, Casaburi R, Carone M, et al. Comparison of gas exchange, lactate, and lactic acidosis thresholds in patients with chronic obstructive pulmonary disease. Am Rev Respir Dis 1993; 148: 622-626.

Pleguezuelos E, Esquinas C, Moreno E, et al. Muscular dysfunction in COPD: systemic effect or deconditioning? Lung 2016; 194: 249-257.

O'Donnell DE, Laveneziana $\mathrm{P}$, Webb $\mathrm{K}$, et al. Chronic obstructive pulmonary disease: clinical integrative physiology. Clin Chest Med 2014; 35: 51-69.

Laveneziana P, Palange P, Ora J, et al. Bronchodilator effect on ventilatory, pulmonary gas exchange, and heart rate kinetics during high-intensity exercise in COPD. Eur J Appl Physiol 2009; 107: 633-643.

Laveneziana P, Valli G, Onorati P, et al. Effect of heliox on heart rate kinetics and dynamic hyperinflation during high-intensity exercise in COPD. Eur J Appl Physiol 2011; 111: 225-234.

Chiappa GR, Borghi-Silva A, Ferreira LF, et al. Kinetics of muscle deoxygenation are accelerated at the onset of heavy-intensity exercise in patients with COPD: relationship to central cardiovascular dynamics. J Appl Physiol (1985) 2008; 104: 1341-1350.

Vasilopoulou MK, Vogiatzis I, Nasis I, et al. On- and off-exercise kinetics of cardiac output in response to cycling and walking in COPD patients with GOLD Stages I-IV. Respir Physiol Neurobiol 2012; 181: 351-358.

Saey D, Debigaré R, Leblanc P, et al. Contractile leg fatigue after cycle exercise: a factor limiting exercise in patients with chronic obstructive pulmonary disease. Am J Respir Crit Care Med 2003; 168: 425-430.

Gandevia SC. The perception of motor commands or effort during muscular paralysis. Brain 1982; 105: 151-159.

Gandevia SC, Killian KJ, Campbell EJ. The effect of respiratory muscle fatigue on respiratory sensations. Clin Sci 1981; 60: 463-466.

Guenette JA, Chin RC, Cheng S, et al. Mechanisms of exercise intolerance in global initiative for chronic obstructive lung disease grade 1 COPD. Eur Respir J 2014; 44: 1177-1187.

Jolley CJ, Luo YM, Steier J, et al. Neural respiratory drive and breathlessness in COPD. Eur Respir J 2015; 45: 355-364.

Potter WA, Olafsson S, Hyatt RE. Ventilatory mechanics and expiratory flow limitation during exercise in patients with obstructive lung disease. J Clin Invest 1971; 50: 910-919.

Dodd DS, Brancatisano TP, Engel LA. Effect of abdominal strapping on chest wall mechanics during exercise in patients with severe chronic air-flow obstruction. Am Rev Respir Dis 1985; 131: 816-821.

O'Donnell DE, Guenette JA, Maltais F, et al. Decline of resting inspiratory capacity in COPD: the impact on breathing pattern, dyspnea, and ventilatory capacity during exercise. Chest 2012; 141: 753-762.

Guenette JA, Chin RC, Cory JM, et al. Inspiratory capacity during exercise: measurement, analysis, and interpretation. Pulm Med 2013; 2013: 956081.

Killian KJ, Jones NL. Respiratory muscles and dyspnea. Clin Chest Med 1988; 9: 237-248.

Johnson BD, Weisman IM, Zeballos RJ, et al. Emerging concepts in the evaluation of ventilatory limitation during exercise: the exercise tidal flow-volume loop. Chest 1999; 116: 488-503.

Dominelli PB, Foster GE, Guenette JA, et al. Quantifying the shape of the maximal expiratory flow-volume curve in mild COPD. Respir Physiol Neurobiol 2015; 219: 30-35.

Neder JA, O’Donnell CD, Cory J, et al. Ventilation distribution heterogeneity at rest as a marker of exercise impairment in mild-to-advanced COPD. COPD 2015; 12: 249-256.

Diaz O, Villafranca C, Ghezzo H, et al. Role of inspiratory capacity on exercise tolerance in COPD patients with and without tidal expiratory flow limitation at rest. Eur Respir J 2000; 16: 269-275.

Ofir D, Laveneziana P, Webb KA, et al. Mechanisms of dyspnea during cycle exercise in symptomatic patients with GOLD stage I chronic obstructive pulmonary disease. Am J Respir Crit Care Med 2008; 177: 622-629.

Chin RC, Guenette JA, Cheng S, et al. Does the respiratory system limit exercise in mild chronic obstructive pulmonary disease? Am J Respir Crit Care Med 2013; 187: 1315-1323.

Dempsey JA. Limits to ventilation (for sure!) and exercise (maybe?) in mild chronic obstructive pulmonary disease. Am J Respir Crit Care Med 2013; 187: 1282-1283.

Means JH. Dyspnoea, Medicine Monographs 3. Baltimore, Williams \& Wilkins, 1924; pp. 309-416.

Elbehairy AF, Guenette JA, Faisal A, et al. Mechanisms of exertional dyspnoea in symptomatic smokers without COPD. Eur Respir J 2016; 48: 694-705.

Gandevia B, Hugh-Jones P. Terminology for measurements of ventilatory capacity. A report to the Thoracic Society. Thorax 1957; 12: 290-293.

Leblanc P, Summers E, Inman MD, et al. Inspiratory muscles during exercise: a problem of supply and demand. J Appl Physiol 1988; 64: 2482-2489.

O’Donnell DE, Revill SM, Webb KA. Dynamic hyperinflation and exercise intolerance in chronic obstructive pulmonary disease. Am J Respir Crit Care Med 2001; 164: 770-777.

Laveneziana P, Webb KA, Wadell K, et al. Does expiratory muscle activity influence dynamic hyperinflation and exertional dyspnea in COPD? Respir Physiol Neurobiol 2014; 199: 24-33.

Killian KJ, Gandevia SC, Summers E, et al. Effect of increased lung volume on perception of breathlessness, effort, and tension. J Appl Physiol 1984; 57: 686-691.

Chen Z, Eldridge FL, Wagner PG. Respiratory-associated thalamic activity is related to level of respiratory drive. Respir Physiol 1992; 90: 99-113. 
O'Donnell DE, Hamilton AL, Webb KA. Sensory-mechanical relationships during high-intensity, constant-work-rate exercise in COPD. J Appl Physiol 2006; 101: 1025-1035. limitation: pathophysiologic mechanisms. Am J Respir Crit Care Med 1997; 155: 109-115.

57 Laveneziana P, Webb KA, Ora J, et al. Evolution of dyspnea during exercise in COPD: impact of critical volume constraints. Am J Respir Crit Care Med 2011; 184: 1367-1373.

58 O'Donnell DE, Hong HH, Webb KA. Effects of chest wall restriction and deadspace loading on dyspnea and exercise tolerance in healthy normals. J Appl Physiol 2000; 88: 1859-1869.

59 Manning HL, Shea SA, Schwartzstein RM, et al. Reduced tidal volume increases 'air hunger' at fixed $\mathrm{PCO}_{2}$ in ventilated quadriplegics. Respir Physiol 1992; 90: 19-30.

60 Opie L, Smith A, Spalding J. Conscious appreciation of the effects produced by independent changes of ventilation volume and of end-tidal $\mathrm{PCO}_{2}$ in paralysed patients. J Physiol 1959; 149: 494-499.

61 Schwartzstein RM, Simon PM, Weiss JW, et al. Breathlessness induced by dissociation between ventilation and chemical drive. Am Rev Respir Dis 1989; 139: 1231-1237.

62 Eldridge F, Chen Z. Respiratory-associated rhythmic firing of midbrain neurons is modulated by vagal input. Respir Physiol 1992; 90: 31-46.

63 Mahler DA, Murray JA, Waterman LA, et al. Endogenous opioids modify dyspnoea during treadmill exercise in patients with COPD. Eur Respir J 2009; 33: 771-777.

64 Banzett RB, Pedersen SH, Schwartzstein RM, et al. The affective dimension of laboratory dyspnea: air hunger is more unpleasant than work/effort. Am J Respir Crit Care Med 2008; 177: 1384-1390.

65 von Leupoldt A, Sommer T, Kegat S, et al. Dyspnea and pain share emotion-related brain network. Neuroimage 2009; 48: 200-206.

66 Davenport PW, Vovk A. Cortical and subcortical central neural pathways in respiratory sensations. Respir Physiol Neurobiol 2009; 167: 72-86.

67 von Leupoldt A, Dahme B. Cortical substrates for the perception of dyspnea. Chest 2005; 128: $345-354$.

68 von Leupoldt A, Sommer T, Kegat S, et al. The unpleasantness of perceived dyspnea is processed in the anterior insula and amygdala. Am J Respir Crit Care Med 2008; 177: 1026-1032.

69 Evans KC, Banzett RB, Adams L, et al. BOLD fMRI identifies limbic, paralimbic, and cerebellar activation during air hunger. J Neurophysiol 2002; 88: 1500-1511.

70 Pattinson K. Basic science for the chest physician: functional brain imaging in respiratory medicine. Thorax 2015 70: 598-600.

71 Mahler DA, Weinberg DH, Wells CK, et al. The measurement of dyspnea. Contents, interobserver agreement, and physiologic correlates of two new clinical indexes. Chest 1984; 85: 751-758.

72 Roig M, Eng JJ, MacIntyre DL, et al. Deficits in muscle strength, mass, quality, and mobility in people with chronic obstructive pulmonary disease. J Cardiopulm Rehabil Prev 2011; 31: 120-124.

73 Ciavaglia CE, Guenette JA, Langer D, et al. Differences in respiratory muscle activity during cycling and walking do not influence dyspnea perception in obese patients with COPD. J Appl Physiol (1985) 2014; 117: 1292-1301.

74 Ciavaglia CE, Guenette JA, Ora J, et al. Does exercise test modality influence dyspnoea perception in obese patients with COPD? Eur Respir J 2014; 43: 1621-1630.

75 Ora J, Laveneziana $\mathrm{P}$, Wadell $\mathrm{K}$, et al. Effect of obesity on respiratory mechanics during rest and exercise in COPD. J Appl Physiol (1985) 2011; 111: 10-19.

76 O'Donnell DE, Ciavaglia CE, Neder JA. When obesity and chronic obstructive pulmonary disease collide. Physiological and clinical consequences. Ann Am Thorac Soc 2014; 11: 635-644. exercise. Respir Physiol Neurobiol 2016; 221: 41-48.

78 Arbex FF, Alencar MC, Souza A, et al. Exercise ventilation in COPD: influence of systolic heart failure. COPD 2016; in press [DOI: 10.1080/15412555.2016.1174985].

79 Oliveira MF, Zelt JT, Jones JH, et al. Does impaired $\mathrm{O}_{2}$ delivery during exercise accentuate central and peripheral fatigue in patients with coexistent COPD-CHF? Front Physiol 2014; 5: 514.

80 Borg GA. Psychophysical bases of perceived exertion. Med Sci Sports Exerc 1982; 14: 377-381.

81 Wilson RC, Jones PW. A comparison of the visual analogue scale and modified Borg scale for the measurement of dyspnoea during exercise. Clin Sci (Lond) 1989; 76: 277-282.

82 O'Donnell DE, Travers J, Webb KA, et al. Reliability of ventilatory parameters during cycle ergometry in multicentre trials in COPD. Eur Respir J 2009; 34: 866-874.

83 Killian KJ, Summers E, Jones NL, et al. Dyspnea and leg effort during incremental cycle ergometry. Am Rev Respir Dis 1992; 145: 1339-1345.

84 Carrieri-Kohlman V, Gormley JM, Douglas MK, et al. Exercise training decreases dyspnea and the distress and anxiety associated with it. Monitoring alone may be as effective as coaching. Chest 1996; 110: 1526-1535.

85 Wadell K, Webb KA, Preston ME, et al. Impact of pulmonary rehabilitation on the major dimensions of dyspnea in COPD. COPD 2013; 10: 425-435.

86 Mahler DA, Gifford AH, Waterman LA, et al. Mechanism of greater oxygen desaturation during walking compared with cycling in patients with COPD. Chest 2011; 140: 351-358.

87 Palange $\mathrm{P}$, Forte $\mathrm{S}$, Onorati $\mathrm{P}$, et al. Ventilatory and metabolic adaptations to walking and cycling in patients with COPD. J Appl Physiol 2000; 88: 1715-1720.

88 Hsia D, Casaburi R, Pradhan A, et al. Physiological responses to linear treadmill and cycle ergometer exercise in COPD. Eur Respir J 2009; 34: 605-615.

89 Borel B, Provencher S, Saey D, et al. Responsiveness of various exercise-testing protocols to therapeutic interventions in COPD. Pulm Med 2013; 2013: 410748.

90 Holm SM, Rodgers W, Haennel RG, et al. Effect of modality on cardiopulmonary exercise testing in male and female COPD patients. Respir Physiol Neurobiol 2014; 192: 30-38.

91 Sue DY, Wasserman K, Moricca RB, et al. Metabolic acidosis during exercise in patients with chronic obstructive pulmonary disease. Use of the V-slope method for anaerobic threshold determination. Chest 1988; 94: 931-938.

92 American Thoracic Society; American College of Chest Physicians. ATS/ACCP Statement on cardiopulmonary exercise testing. Am J Respir Crit Care Med 2003; 167: 211-277. 
Whipp BJ, Ward SA, Wasserman K. Ventilatory responses to exercise and their control in man. Am Rev Respir Dis 1984; 129: S17-S20.

Sun X-G, Hansen JE, Garatachea N, et al. Ventilatory efficiency during exercise in healthy subjects. Am J Respir Crit Care Med 2002; 166: 1443-1448.

ERS Task Force, Palange P, Ward SA, et al. Recommendations on the use of exercise testing in clinical practice. Eur Respir J 2007; 29: 185-209.

Paoletti P, De Filippis F, Fraioli F, et al. Cardiopulmonary exercise testing (CPET) in pulmonary emphysema. Respir Physiol Neurobiol 2011; 179: 167-173.

Teopompi E, Tzani P, Aiello M, et al. Excess ventilation and ventilatory constraints during exercise in patients with chronic obstructive pulmonary disease. Respir Physiol Neurobiol 2014; 197: 9-14.

Woodruff PG, Barr RG, Bleecker E, et al. Clinical significance of symptoms in smokers with preserved pulmonary function. $N$ Engl J Med 2016; 374: 1811-1821.

Regan EA, Lynch DA, Curran-Everett D, et al. Clinical and radiologic disease in smokers with normal spirometry. JAMA Intern Med 2015; 175: 1539-1549.

Furlanetto KC, Mantoani LC, Bisca G, et al. Reduction of physical activity in daily life and its determinants in smokers without airflow obstruction. Respirology 2014; 19: 369-375.

Elbehairy AF, Raghavan N, Cheng S, et al. Physiologic characterization of the chronic bronchitis phenotype in GOLD grade IB COPD. Chest 2015; 147: 1235-1245.

O’Donnell DE, D’Arsigny C, Fitzpatrick M, et al. Exercise hypercapnia in advanced chronic obstructive pulmonary disease: the role of lung hyperinflation. Am J Respir Crit Care Med 2002; 166: 663-668.

Peters MM, Webb KA, O'Donnell DE. Combined physiological effects of bronchodilators and hyperoxia on dyspnea and exercise performance in normoxic COPD. Thorax 2006; 61: 559-567.

Puente-Maestu L, Palange P, Casaburi R, et al. Use of exercise testing in the evaluation of interventional efficacy: an official ERS statement. Eur Respir J 2016; 47: 429-460.

Neder JA, Jones PW, Nery LE, et al. Determinants of the exercise endurance capacity in patients with chronic obstructive pulmonary disease. The power-duration relationship. Am J Respir Crit Care Med 2000; 162: 497-504. O'Donnell DE, Voduc N, Fitzpatrick M, et al. Effect of salmeterol on the ventilatory response to exercise in chronic obstructive pulmonary disease. Eur Respir J 2004; 24: 86-94.

O'Donnell DE, Laveneziana P, Ora J, et al. Evaluation of acute bronchodilator reversibility in patients with symptoms of GOLD stage I COPD. Thorax 2009; 64: 216-223.

Casaburi R, Maltais F, Porszasz J, et al. Effects of tiotropium on hyperinflation and treadmill exercise tolerance in mild to moderate chronic obstructive pulmonary disease. Ann Am Thorac Soc 2014; 11: 1351-1361.

Gagnon P, Saey D, Provencher S, et al. Walking exercise response to bronchodilation in mild COPD: a randomized trial. Respir Med 2012; 106: 1695-1705.

Mahler D, Decramer M, D’Urzo A, et al. Dual bronchodilation with QVA149 reduces patient-reported dyspnoea in COPD: the BLAZE study. Eur Respir J 2014; 43: 1599-1609.

O’Donnell DE, Forkert L, Webb KA. Evaluation of bronchodilator responses in patients with "irreversible" emphysema. Eur Respir J 2001; 18: 914-920.

Newton MF, O'Donnell DE, Forkert L. Response of lung volumes to inhaled salbutamol in a large population of patients with severe hyperinflation. Chest 2002; 121: 1042-1050.

Celli B, ZuWallack R, Wang S, et al. Improvement in resting inspiratory capacity and hyperinflation with tiotropium in COPD patients with increased static lung volumes. Chest 2003; 124: 1743-1748.

O'Donnell DE, Flüge T, Gerken F, et al. Effects of tiotropium on lung hyperinflation, dyspnoea and exercise tolerance in COPD. Eur Respir J 2004; 23: 832-840.

Maltais F, Hamilton A, Marciniuk D, et al. Improvements in symptom-limited exercise performance over $8 \mathrm{~h}$ with once-daily tiotropium in patients with COPD. Chest 2005; 128: 1168-1178.

Deesomchok A, Webb KA, Forkert L, et al. Lung hyperinflation and its reversibility in patients with airway obstruction of varying severity. COPD 2010; 7: 428-437.

Maltais F, Celli B, Casaburi R, et al. Aclidinium bromide improves exercise endurance and lung hyperinflation in patients with moderate to severe COPD. Respir Med 2011; 105: 580-587.

Verkindre C, Bart F, Aguilaniu B, et al. The effect of tiotropium on hyperinflation and exercise capacity in chronic obstructive pulmonary disease. Respiration 2006; 73: 420-427.

Tantucci C, Duguet A, Similowski T, et al. Effect of salbutamol on dynamic hyperinflation in chronic obstructive pulmonary disease patients. Eur Respir J 1998; 12: 799-804.

Belman MJ, Botnick WC, Shin JW. Inhaled bronchodilators reduce dynamic hyperinflation during exercise in patients with chronic obstructive pulmonary disease. Am J Respir Crit Care Med 1996; 153: 967-975.

Beeh KM, Singh D, Di Scala L, et al. Once-daily NVA237 improves exercise tolerance from the first dose in patients with COPD: the GLOW3 trial. Int J Chron Obstruct Pulmon Dis 2012; 7: 503-513.

Casaburi R, Patessio A, Ioli F, et al. Reductions in exercise lactic acidosis and ventilation as a result of exercise training in patients with obstructive lung disease. Am Rev Respir Dis 1991; 143: 9-18.

O’Donnell DE, McGuire M, Samis L, et al. Impact of exercise reconditioning on breathlessness in severe chronic airflow limitation. Am J Respir Crit Care Med 1995; 152: 2005-2013.

O’Donnell DE, McGuire M, Samis L, et al. Effects of general exercise training on ventilatory and peripheral muscle strength and endurance in chronic airflow limitation. Am J Respir Crit Care Med 1998; 157: $1489-1497$.

Lan CC, Chu WH, Yang MC, et al. Benefits of pulmonary rehabilitation in patients with COPD and normal exercise capacity. Respir Care 2013; 58: 1482-1488.

O’Donnell DE, D'Arsigny C, Webb KA. Effects of hyperoxia on ventilatory limitation during exercise in advanced chronic obstructive pulmonary disease. Am J Respir Crit Care Med 2001; 163: 892-898.

O'Donnell DE, Bain DJ, Webb KA. Factors contributing to relief of exertional breathlessness during hyperoxia in chronic airflow limitation. Am J Respir Crit Care Med 1997; 155: 530-535.

Somfay A, Porszasz J, Lee SM, et al. Dose-response effect of oxygen on hyperinflation and exercise endurance in nonhypoxaemic COPD patients. Eur Respir J 2001; 18: 77-84.

Uronis HE, Ekström MP, Currow DC, et al. Oxygen for relief of dyspnoea in people with chronic obstructive pulmonary disease who would not qualify for home oxygen: a systematic review and meta-analysis. Thorax 2015; 70: $492-494$. 
130 Johnson $\mathrm{M}$, Bland J, Oxberry S, et al. Opioids for chronic refractory breathlessness: patient predictors of beneficial response. Eur Respir J 2013; 42: 758-766.

131 Jensen D, Alsuhail A, Viola R, et al. Inhaled fentanyl citrate improves exercise endurance during high-intensity constant work rate cycle exercise in chronic obstructive pulmonary disease. J Pain Symptom Manage 2012; 43: 706-719.

132 Ekström M, Nilsson F, Abernethy AA, et al. Effects of opioids on breathlessness and exercise capacity in chronic obstructive pulmonary disease. A systematic review. Ann Am Thorac Soc 2015; 12: 1079-1092.

133 Rocker GM, Simpson AC, Young J, et al. Opioid therapy for refractory dyspnea in patients with advanced chronic obstructive pulmonary disease: patients' experiences and outcomes. CMAJ Open 2013; 1: E27-E36.

134 Mahler DA. Opioids for refractory dyspnea. Expert Rev Respir Med 2013; 7: 123-134.

135 Vozoris NT, Wang X, Fischer HD, et al. Incident opioid drug use among older adults with chronic obstructive pulmonary disease: a population-based cohort study. Br J Clin Pharmacol 2016; 81: 161-170.

136 Somfay A, Pórszász J, Lee SM, et al. Effect of hyperoxia on gas exchange and lactate kinetics following exercise onset in nonhypoxemic COPD patients. Chest 2002; 121: 393-400.

137 Dean NC, Brown JK, Himelman RB, et al. Oxygen may improve dyspnea and endurance in patients with chronic obstructive pulmonary disease and only mild hypoxemia. Am Rev Respir Dis 1992; 146: 941-945.

138 Morrison DA, Stovall JR. Increased exercise capacity in hypoxemic patients after long-term oxygen therapy. Chest 1992; 102: 542-550.

139 Bye PT, Esau SA, Levy RD, et al. Ventilatory muscle function during exercise in air and oxygen in patients with chronic air-flow limitation. Am Rev Respir Dis 1985; 132: 236-240.

140 Criner GJ, Celli BR. Ventilatory muscle recruitment in exercise with $\mathrm{O}_{2}$ in obstructed patients with mild hypoxemia. J Appl Physiol 1987; 63: 195-200.

141 Ekström MP, Bornefalk-Hermansson A, Abernethy AP, et al. Safety of benzodiazepines and opioids in very severe respiratory disease: national prospective study. BMJ 2014; 348: g445.

142 Simon ST, Higginson IJ, Booth S, et al. Benzodiazepines for the relief of breathlessness in advanced malignant and non-malignant diseases in adults. Cochrane Database Syst Rev 2010; 1: CD007354. 